\title{
Veterinary Dermatology
}

\section{Quantitative Real time polymerase chain reaction (qPCR) and RNAscope in situ hybridization (RNA-ISH) as effective tools to diagnose feline herpesvirus-1 associated dermatitis.}

\begin{tabular}{|c|l|}
\hline Journal: & Veterinary Dermatology \\
\hline Manuscript ID & Draft \\
\hline Weywords: Manuscript type: & Scientific Paper \\
\hline feline, herpesvirus-1 associated dermatitis, qPCR, RNA in situ \\
hybridization, skin
\end{tabular}




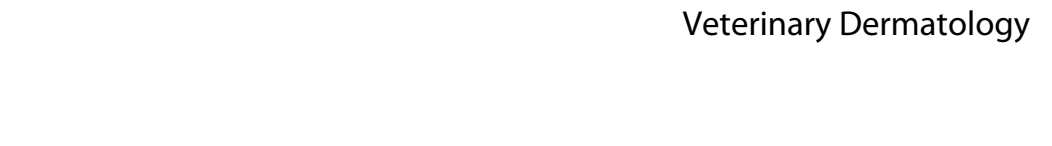




\section{Abstract}

Background-Felid herpesvirus type 1 (FHV-1) associated dermatitis is characterized by facial and nasal involvement; clinical and histopathological manifestations may overlap with other feline dermatitides.

Objective-To evaluate the realibility of qPCR-2- $\Delta \Delta \mathrm{Cq}$ and RNAscope In situ Hybridization (RNA-ISH) methods to diagnose FHV-1-associated dermatitis, in formalin fixed paraffin embedded (FFPE) tissues.

Animals-Twenty FFPE samples from cats with facial dermatitis (sixteen) and controls (four) were studied.

Methods-Based on histopathological features, cases were separated in: Group 1samples with herpetic dermatitis (four cats); Group 2-samples with nonherpetic facial dermatitis (six); Group 3-samples with facial dermatitis of ambiguous nature (allergic or viral) (six); Group 4-samples from healthy cats (four). A relative quantification using the $2^{-\Delta \Delta \mathrm{Ca}}$ method was used to estimate as the "upregulation" of each FHV-1 target viral gene copies (glycoprotein-B and thymidine-kinase) relative to reference gene. Detection of FHV-1 mRNA was performed using the RNAscope 2.5 detection kit. Results-By ${ }^{-}-\Delta \Delta \mathrm{Cq}$ analysis, upregulation of both $\mathrm{FHV}-1$ genes was observed in all samples from Group 1 and 2/6 from Group 3. No upregulation was identified in samples from Group 2 and 4. Positive mRNA hybridization signal was observed in all cases from Group 1 and 2 cases of Group 3. No positivity was observed in samples from Group 2 and 4.

Conclusions and clinical importance-qPCR $2^{-\Delta \Delta C q}$ analysis and RNA-ISH can identify FHV-1 genome as causative agent of the associated dermatitis, even where the inclusion bodies are not detectable. Both techniques are extensively functional in retrospective studies and may be proposed for research and diagnostic purposes. 


\section{Introduction}

Felid herpesvirus type 1 (FHV-1) belongs to the Varicellovirus genus of the Herpesviridae family, a large and varied group of enveloped DNA viruses characterized by their ability to generate latent infections. ${ }^{1}$ FHV-1 is a worldwide pathogen responsible of upper respiratory tract infection, ocular disease and dermatitis in felids. ${ }^{2}$ The FHV-1-associated dermatitis is characterized by facial and nasal involvement with vescicles, ulcers, crusts and stomatitis. ${ }^{3}$ Lesions are commonly localised on the face, expecially on the nose, muzzle, lips and periorbital areas. $3,4,5$ These clinical manifestations overlap with other feline dermatitides including hypersensitivity disorders such as mosquito bite hypersitivity, eosinophilic granuloma complex, cutaneous adverse food reactions and feline atopic syndrome. ${ }^{6}$ The therapy for the aformentioned hypersensitivity disorders requires topical and oral glucocorticoids or other immunomodulatory drugs which are contraindicated in the case of viral etiology. ${ }^{7}$ Provide a correct diagnosis for FHV-1 associated dermatitis is therefore strictly necessary to identify the specific therapeuthical approach.

Diagnosis is based on different detection methods mainly based on histopathology, immunohistochemistry (IHC) or PCR. ${ }^{3,8-13}$ Histopathology and IHC are widely used to diagnose FHV-1-associated dermatitis in cats, relying on the detection of nuclear inclusion bodies and viral protein in intact epithelial cells, respectively. However, due to the severe inflammation and necrosis often observed in these skin biopsies, inclusion bodies may be easily overlooked, leading to false negative results. ${ }^{6,12}$ Alongside, PCR assays have been introduced to detect FHV-1 nucleic acid from several substrates including biopsy specimens. ${ }^{3,12,14,15}$ However, the interpretation of any PCR result could be affected by several factors such as: the low level of viral shedding, viral latency and the possibility of detection of viral DNA in individuals subjected to modified-live virus vaccination. ${ }^{12,16,17}$ In order to overcome this issue, the use of a quantitative real time PCR (qPCR) has been proposed assuming that high viral load values could reflect the active viral replication and virus infection. ${ }^{10}$ Giving these premises, the aims of this retrospective study were: (i) to evaluate the realibility of the qPCR $2^{-\Delta \Delta C a}$ method for the diagnosis of FHV-1-associated facial dermatitis, in comparison to conventional PCR; (ii) to detect and localize FHV-1 messenger RNA (mRNA) in feline formalin fixed paraffin embedded (FFPE) tissues, by the RNAscope in situ hybridization (RNA-ISH).

This study will add information on feasibility of different methods employed for the diagnosis of herpesvirus induced dermatitis.

\section{Materials and Methods}

\section{Sample collection and histopathological evaluation}

Twenty FFPE skin biopsy samples from cats with history of facial dermatitis were retrieved from the dermatopathology archive of "this information will be provided after the revision of the manuscript". Signalment and lesion distribution data were included for all cases. Tissue sections ( $4 \mu \mathrm{m}$ thick) were routinely stained with hematoxylin and eosin and histopathological lesions were investigated to generate study groups. The groups were characterized on the basis of estabilished histopathological features such as epithelial and follicular inclusion bodies, keratinocyte aspecific cytopatic effects, epithelial and follicular necrosis, ulcers, 
vescicles, and eosinophilic infiltrates. Based on clinical and histopathological evaluation three study groups were generated: samples with a diagnosis of herpesvirus dermatitis, with evidence of inclusion bodies in the epithelial cells of the epidermis and the follicular wall, as well as in the sebaceous glands (Group 1); samples with non-herpetic facial dermatitis, characterized by eosinophilic or mastocitic dermatitis, with no evidence of inclusion bodies, cytopatic effects and follicular necrosis, consistent with an allergic condition (Group 2); samples with facial dermatitis of ambiguous nature (allergic or viral), characterized by epidermal and follicular necrosis and/or keratinocyte cytopatic effects, without evidence of inclusion bodies (Group 3). An additional group, including skin samples with no histopatological lesions, from the facial area of 4 clinically healthy cats vaccinated against FHV-1, was used as negative control (Group 4).

\section{PCR assays}

\section{Sampling material}

Three $10 \mu \mathrm{m}$ thick FFPE serial sections from each sample were cut with a microtome and directly collected in a $1,5 \mathrm{ml}$ DNase free tube. To prevent carryover of contaminating DNA the microtome overlay was covered with a piece of adhesive tape and a different blade was used for each sample.

\section{DNA extraction}

DNA extraction was performed using DNeasy Blood and Tissue kit (Qiagen, Hilden, Germany) following manufacturer's instruction and applying a preliminary removal of paraffin by extraction with xylene. DNAs were eluted in $50 \mu$ and stored at $-20^{\circ} \mathrm{C}$ until molecular analysis. DNA was also extracted from 2 different commercially available FHV-1 live attenuated vaccines (Feligen Cr/p Virbac; Nobivac Tricat trio MSD Animal Health) as control templates.

\section{Real time PCR technique (qPCR)}

The extracted DNAs were amplified using specific set of primers targeting two viral genes: Glycoprotein B (gB) and Thymidine Kinase (TK)(Suppl). ${ }^{10,11}$ To normalize the amount of DNA used for each sample, in order to achieve a correct quantification of viral target, a qPCR under the same condition as for FHV-1, but with a specific set of primers for the Felis catus reference ribosomal 28 s housekeeping gene, ${ }^{11}$ was run in parallel (Suppl 1).

Melting curve analysis was performed in conjunction with the FHV-1 amplification protocol to determine whether non-specific products were amplified during the reaction. The specificity of the melting curve was compared to melting curve values obtained from DNA extracted from the 2 different vaccines. Moreover, dilutions of DNA extracted from vaccines were serially diluted $(1: 10 ; 1: 100 ; 1: 1000 ; 1: 10000)$ in order to calculate the efficiency for $\mathrm{gB}$ and TK primer set. Similar dilution series were prepared with DNA extracted from the control skin samples to calculate the housekeeping efficiency.

A relative quantification $(R Q)$ using the $2^{-\Delta \Delta C q}$ method was adapted to estimate in each sample the fold change referred as "upregulation", of each FHV-1 target viral gene copies relative to reference gene. ${ }^{18,19}$ In details, the presence of the target viral gene as well as the housekeeping gene were measured and expressed as $\mathrm{Cq}_{1}$ and $\mathrm{Cq}_{2}$ values, respectively; a $\Delta \mathrm{Cq}$ value was generated considering the difference between 
$130 \mathrm{Cq}_{2}$ and $\mathrm{Cq}_{1} . \mathrm{A} \Delta \Delta \mathrm{Cq}$ value was calculated by the difference between the $\Delta \mathrm{Cq}$ value of each sample and the mean $\Delta \mathrm{Cq}$ value obtained from the healthy cats (Group 4). Finally, the $2^{-\Delta \Delta \mathrm{Cq}}$ value represents a normalized measure of DNA viral quantity and was calculated for each sample. The assays were performed in Rotorgene thermocycler (Corbett Research, Sydney, Australia) using SSCO SYBR Green master mix (Biorad, Hercules, USA) and $5 \mu$ of extracted DNA as template. All samples were tested in duplicate and the results were calculated using the mean $\mathrm{Cq}$ values.

\section{Conventional PCR}

All the samples were tested by conventional PCR using the same set of primer used for the qPCR for amplification of $\mathrm{gB}$ and TK viral genes. ${ }^{10,11}$ The PCR protocol was performed by 35 cycles with annealing step of $60^{\circ} \mathrm{C}$ for $30 \mathrm{sec}$ using HotStartTaq plus PCR kit (Qiagen). The PCR products were analyzed by $1.5 \%$ agarose gel electrophoresis analysis.

\section{$\underline{\text { RNA-ISH }}$}

Detection of FHV-1 mRNA was performed using the RNAscope 2.5 detection kit and the $30 Z Z$ V-FeHV1-ICP0 probe from Advanced Cellular Diagnostics (ACD, Newark, $\mathrm{CA}$ ), that targets the sequence between nucleotides 103924 and 105661 (accession number FJ478159.2). RNA-ISH was performed by the automated immunostainer Bond $\mathrm{RX}$ (Leica Biosystem, Nussloch $\mathrm{GmbH}$ ) on $4 \mu \mathrm{m}$ thick FFPE serial sections, according to the manufacturer's protocol. Briefly, sections were deparaffinized and pretreated with heat and protease before hybridization. Successful hybridization requires binding of adjacent probe pairs on the targeted nucleic acid, initiating a cascade that leads to deposition of diaminobenzidine. The final deposit is visualized as brown, punctate precipitate.

From each sample, three adjacent sections were stained using probes for FeHV-1ICP0, Fc-PPIB (peptidylprolyl isomerase B (cyclophilin B)), and negative control probe_dapB (Bacillus subtilis dihydrodipicolinate reductase (dapB) gene). PPIB was used as an endogenous control to assess RNA integrity, while the bacterial gene dapB served as a negative control to assess background staining.

\section{Results}

\section{Sample collection and histopathological evaluation}

Data of the signalment and lesion distribution are reported in table 1 . By histopathology, 4 cases were assigned to Group 1, 6 cases were included in Group 2, 6 cases in Group 3, and 4 cases in the control Group 4. The results of histopathological evaluation are detailed in table 2.

\section{$\underline{\text { Real time PCR technique (qPCR) }}$}

All specimens resulted appropriate for qPCR analysis since Felis catus 28 s reference gene resulted positive to specific real time assay. Efficiency values for each assay were: 28s housekeeping genes $96 \%$, gB 97\% and and TK 98\%. Specific amplification signals were detected for both gB and TK assays in numerous samples belonging to all groups, but using the $2^{-\Delta \Delta C q}$ analysis, in some of these 
samples the viral genes were not considered quantitatively sufficient (upregulated), respect to the negative control group as shown in table 3.

By the $2^{-\Delta \Delta \mathrm{Cq}}$ analysis, upregulation of both $\mathrm{FHV}-1$ genes were observed in all samples in positive control Group 1, while no upregulation was identified for samples belonging to Group 2. In Group 3, 2/6 samples showed both gB and TK genes upregulation, suggesting the FHV-1 as the causative agent of the skin lesion reported (table 3 ).

\section{Conventional PCR}

Conventional PCR identified a total of $12 / 20$ and $9 / 20$ positive samples for $\mathrm{gB}$ and TK gene, respectively. All samples belonging to group 1 resulted positive for both viral genes. In group 2, 1 sample showed gB gene amplification only and 1 sample showed both gB and TK gene amplification. In group 3, five and four out of 6 samples were positive for $\mathrm{gB}$ and TK gene amplification, respectively. All samples positive to TK also scored positive to gB gene. In group 4 one sample was positive for gB gene amplification (Table 3).

\section{$\underline{\text { RNA-ISH }}$}

Positive hybridization signal due to the detection of viral mRNA, was observed in all the cases belonging to group 1, as well as in 2 cases of group 3. No positivity was observed in samples of group 2 and 4 . Positive keratinocytes were mainly observed at the level of epidermal ulceration and follicular necrosis (figure 1a-b), as well as in keratinocytes containing inclusion bodies and in sebaceous glands. Positivity was seen as strong round nuclear and punctate cytoplasmic brown deposits in infected cells (figure 2a). All the samples incubated with the PPIB probe showed good mRNA integrity (figure $2 b$ ), and were negative by the DapB control probe (figure $2 c$ ). Detailed results of $\mathrm{CISH}$ are reported in table 3 .

\section{$\underline{\text { Histopathology, conventional PCR, qPCR and RNA-ISH correlations }}$}

Histopathological detection of inclusion bodies in group 1 well correlated with conventional PCR, qPCR and RNA-ISH results. Samples from group 2 did not showed any histological feature referable to herpesvirus induced dermatitis and were negative to both $2^{-\Delta \Delta \mathrm{Cq}} \mathrm{qPCR}$ and RNA-ISH, even though the conventional PCR occasionaly detected viral DNA. Two out of six cases from group 3, showed positive results by conventional PCR, qPCR, and RNA-ISH supporting the diagnosis of herpesviral dermatitis. Three other cases belonging to group 3 were positive for FHV-1 DNA by conventional PCR but negative by qPCR and RNA-ISH. All cases in group 4 were negative to all molecular methods, except one which was positive by conventional PCR. All samples positive to $2^{-\Delta \Delta C q}$ analysis were also positive to conventional PCR. Notably, 6 and 3 samples respectively positive for $\mathrm{gB}$ and TK by conventional PCR, resulted negative to $2^{-\Delta \Delta C q}$ analysis. The qPCR and RNA ISH showed $100 \%$ concordance.

\section{Discussion}

The present study demontrates that the qPCR $2^{-\Delta \Delta C q}$ as well as the RNA-ISH are feasible methods to confirm the diagnosis of FHV-1 associated dermatitis. 
229 Previous research explored the usefulness of immunohistochemistry and conventional

230 PCR in cases where intranuclear inclusions are missing but clinical and histological findings are compatible with FHV-1 dermatitis. ${ }^{12,20}$ In one of these reports, immunohistochemistry showed limited usefullness, since only cases with evident nuclear inclusions were positive, while a higher number of PCR-positive cases was observed. The authors concluded that PCR was useful for initial screening but not sufficient for a definitive diagnosis due to false positives. ${ }^{12}$ Our results are in accordance with these previous reports, since conventional PCR detected viral genome in all the cases from group 1 (with evident inclusion bodies at histopathology), but positive results were also recorded from cases in groups 2, 3 and 4 , even though not confirmed by $2^{-\Delta \Delta \mathrm{Cq}}$ analysis. Overall these findings indicate that conventional PCR overestimates the true role of FHV-1 in causing ulcerative dermatitis, likely due to the presence of latent or vaccinal viral DNA. ${ }^{12,21,22}$ In fact, vaccination for FHV-1 is done with a live attenuated viral strain and classical PCR, amplifying the TK gene, identifies a nuclear sequence that is inserted in the host cell during natural infection but also after vaccination. ${ }^{12}$ Moreover, many strains of epitheliotropic Herpes viruses are characterized by latency. ${ }^{1}$ In mice footpad keratinocytes herpes simplex virus (HSV) DNA was retained for more than two weeks after recovery, indicating that detection of HSV DNA in the skin may reflect recent but not necessarily current viral replication. ${ }^{23}$ Unfortunately, no data about the persistence of the viral genome in feline skin after vaccination or a previous contact, are available to date.

Thus, only quantitative PCR and cellular localization of viral mRNA should be considered reliable methods to achieve the etiological diagnosis, as demonstrated by the present study.

In fact, the qPCR by $2^{-\Delta \Delta C q}$ analysis showed high specificity, correctly identifying all negative samples (group 2 and 4), and high sensitivity showing upregulation of both $\mathrm{gB}$ and TK genes in all positive samples (group 1) as well as in 2 samples of group 3. A possible limitation in qPCR application for routine diagnostics is that a negative control group for each run, is needed to correctly calculate the $2^{-\Delta \Delta \mathrm{Cq}}$ value; thus only specialized laboratories may employ this technique.

These results were fully confirmed by RNA-ISH method; in fact, samples that showed viral genes upregulation exhibited amplifiable FHV-1 mRNA in infected cells, consistent with an active infection, while no RNA-ISH positivity was recorded in negative samples.

Detection of mRNA in FFPE tissue samples by chromogenic RNA-ISH has become a reliable alternative for a wide range of biomarkers in many fields including virology, oncology and neurosciences. ${ }^{24}$ The RNAscope technology is a very sensitive ISH technology, based on ACD's unique patented probe design, which allows specific signal amplification as well as background suppression. The main advantages of the RNAscope technology are that it can be applied on archival FFPE tissue samples, many of the steps are similar to those of IHC, and the stained slides can be visualized under a standard bright-field microscope using chromogenic labels. ${ }^{24}$ On the other hand, the RNAscope technology is more expensive than immunohistochemistry and requires standardization and automatization to obtain the optimization of the results. Even though it is well known that RNA is more degradable than DNA, particularly in FFPE tissues, our results showed good RNA integrity as demonstrated by the PPIB probe, despite the long time of archiving of our samples (ranging from 2004 to 2016). Finally, the RNAScope ISH tecnique showed excellent sensitivity and specificity, and provided good morphological results also in severe 
279 necrotic dermatitis, where the inclusion bodies were not evident at the morphological 280 examination.

In conclusion, our results confirm that conventional FHV-1 PCR results must be

283 interpreted with caution in the diagnostic algorithm of herpesviral induced dermatitis,

284 especially if inclusion bodies are not microscopically evident. On the contrary, qPCR 2-

$285 \Delta \triangle \mathrm{Cq}$ analysis and RNA-ISH can identify the FHV-1 genome as causative agent of the

286 associated dermatitis, and both methods are extensively functional in retrospective research studies but may be also considered in the diagnostic algorithm of FHV-1 associated dermatitis. 
1. Gaskell RM, Dennis PE, Goddard LE et al. Isolation of felid herpesvirus 1 from the trigeminal ganglia of latently infected cats. J Gen Virol 1985; 66:391-394.

2. Gaskell RM, Dawson S, Radford A. Feline Respiratory Disease. In: Green CE, ed. Infectious Diseases of the dog and cat. $4^{\text {th }}$ edition. Elsevier-Saunders 2012; 151162.

3. Hargis AM, Ginn PE, Mansell JEKL et al. Ulcerative facial and nasal dermatitis and stomatitis in cats associated with feline herpesvirus 1. Vet Dermatol 1999; 10:267274.

4. Flecknell PA, Orr CM, Wright Al et al. Skin ulceration associated with herpesvirus infection in cats. Vet Rec 1979; 104:313-315.

5. Gaskell R, Dawson S, Radford A et al. Feline herpesvirus. Vet Res 2007; 38:337354.

6. Gross TL, Ihrke PJ, Walder EJ et al. Skin diseases of the Dog and Cat. Clinical and histopathological diagnosis, 2nd edition. Oxford: Blackwell Science, 2015: 351-352.

7. Sanchez MD, Goldschmidt MH, Mauldin EA. Herpesvirus dermatitis in two cats without facial lesions. Vet Dermatol 2012; 23:171-173.

8. Sykes JE, Browning GF, Anderson G et al. Differential sensitivity of culture and the polymerase chain reaction for detection of feline herpesvirus 1 in vaccinated and unvaccinated cats. Arch Virol 1997; 142:65-74.

9. Weigler BJ, Babineau CA, Sherry B et al. High sensitivity polymerase chain reaction assay for active and latent feline herpesvirus-1 infections in domestic cats. Vet Rec 1997; 140:335-338.

10. Vogtlin A, Fraefel C, Albini S et al. Quantification of feline herpesvirus 1 DNA in ocular fluid samples of clinically diseases cats by real-time taqM PCR. J Clin Microbiol 2002; 40:519-523.

11. Helps C, Reeves N, Egan K et al. Detection of Chlamydophila felis and feline herpesvirus by multiplex real-time PCR analysis. J Clin Microbiol 2003; 41:27342736.

12. Persico $P$, Roccabianca $P$, Corona $A$ et al. Detection of feline herpescirus 1 via polymerase chain reaction and immunohostochemistry in cats with ulcerative dermatitis, eosinophilic granuloma complex reaction patterns and mosquito byte hypersensitivity. Vet Dermatol 2011; 22:521-527.

13. Wang J, Liu L, Wang $\mathrm{J}$ et al. Recombinase Polymerase Amplification Assay-A simple, fast and cost-effective alternative to Real Time PCR for specifica detection of feline herpesvirus-1. PLoS ONE 12; e0166903. doi:10.1371/journal.pone.0166903.

14. Reubel GH, Ramos RA, Hickman MA et al. Detection of active and latent infections using the polymerase chain reaction. Arch Virol 1993; 132:409-420.

15. Stiles J, McDermott M, Bigsby $D$ et al. Used of nested polymerase chain reaction to identify feline herpesvirus in ocular tissue from clinically normal cats and cats with corneal sequestra or conjunctivitis. Am J Vet Res 1997; 58:338-342.

16. Maggs DJ, Clark HE. Relative sensitivity of polymerase chain reaction assays used for detection of feline herpesvirus and commercial vaccines. Am J Vet Res 2005; 66:1550-1555. 
17. Ruch-Gallies RA Veir JK, Hawley JR et al. Results of molecular diagnostic assays targeting feline herpesvirus- 1 and feline calicivirus in adult cats administered modified live vaccine. J Feline Med Surg 2011; 13:541-545.

18. Schmittgen TD, Livak KJ. Analyzing real-time PCR data by the comparative CT method. Nat Protoc 2008; 3:1101-1108.

19. Pfaffl MW, Horgan GW, Dempfle L. Relative expression software tool (REST) for group-wise comparison and statistical analysis of relative expression results in realtime PCR. Nucleic Acids Res 2002; 30: e36

20. Lee M, Bosward KL, Norris JM. Immunohistological evaluation of feline herpesvirus-1 infection in feline eosinophilic dermatoses or stomatitis. J Feline Med Surg 2010; 12:72-79.

21. Parzefall B, Schmahl W, Fischer A et al. Evidence of feline herpesvirus-1 DNA in the vestibular ganglion of domestic cats. Vet $J$ 2010; 184:371-2.

22. Sussman MD, Maes RK, Kruger JM. Vaccination of cats for feline rhinotracheitis results in a quantitative reduction of virulent feline herpesvirus-1 latency load after challenge. Virol 1997; 228:379-82.

23. Simmons A, Bowden R, Slobedman B. Retention of herpes simplex virus DNA sequences in the nuclei of mouse footpad keratinocytes after recovery from primary infection. J Gen Virol 1997; 78:867-71

24. Wang F, Flanagan J, Su N et al. RNAscope: a novel in situ RNA analysis platform for formalin-fixed, paraffin- tissues. J Mol Diagn 2012; 14:22-9. 
Legend for tables and figures

Table 1. Signalment and lesion distribution.

Table 2. Results of histopathological lesion scores

Tab. 3. Conventional PCR, qPCR and $\mathrm{CISH}$ results.

Figure 1. Feline herpesvirus dermatitis, histopathology (case $\mathrm{N}^{\circ} 4$ ). (a) Widespread epidermal ulceration and follicular necrosis with perivascular to interstitial dermal mixed infiltrate (hematoxylin and eosin, x10). (b) Strong brown hybridization signal within keratinocytes of residual epidermis, follicular wall and sebocytes (RNA-ISH, $\mathrm{x} 100)$.

Figure 2. Feline herpesvirus dermatitis, histopathology (case $\left.\mathrm{N}^{\circ} 4\right)$. (a) Strong nuclear and cytoplasmic dot-like hybridization signal for FHV-1 RNA in superficial epidermal keratinocytes. (b) Same area, cytoplasmic fine dot-like hybridization signal for the PPIB probe (RNA integrity) in basal epidermal keratinocytes. (c) Same area, negative result by the DapB control probe. (RNA-ISH, x400) 
Table 1. Signalment and lesion distribution.

\begin{tabular}{|c|c|c|c|c|c|}
\hline $\mathbf{N}^{\circ}$ & Group & Breed & Age & Gender & Distribution \\
\hline 1 & \multirow{4}{*}{1} & $\mathrm{DSH}$ & 1 & MC & Nose \\
\hline 2 & & DSH & 6 & nd & Face \\
\hline 3 & & DSH & 15 & $\mathrm{~F}$ & Nose \\
\hline 4 & & Maine Coon & 6 & $M$ & Nose, Periorbital \\
\hline 5 & \multirow{6}{*}{2} & $\mathrm{DSH}$ & 3 & FC & Cheek \\
\hline 6 & & DSH & nd & nd & Face \\
\hline 7 & & $\mathrm{DSH}$ & 14 & MC & Periorbital \\
\hline 8 & & $\mathrm{DSH}$ & 2 & MC & Cheek \\
\hline 9 & & $\mathrm{DSH}$ & 3 & $\mathrm{~F}$ & Superior lip \\
\hline 10 & & $\mathrm{DSH}$ & 1,5 & nd & Nose \\
\hline 11 & \multirow{6}{*}{3} & $\mathrm{DSH}$ & 11 & $M$ & Muzzle \\
\hline 12 & & DSH & 9 & $\mathrm{FC}$ & Nose \\
\hline 13 & & $\mathrm{DSH}$ & nd & $\mathrm{F}$ & Nose \\
\hline 14 & & DSH & 6 & $M$ & Narix \\
\hline 15 & & DSH & 1 & $M$ & Face \\
\hline 16 & & $\mathrm{DSH}$ & 1 & nd & Face \\
\hline 17 & \multirow{4}{*}{4} & $\mathrm{DSH}$ & 14 & FS & Nose \\
\hline 18 & & $\mathrm{DSH}$ & 10 & nd & Nose \\
\hline 19 & & $\mathrm{DSH}$ & nd & nd & Nose \\
\hline 20 & & $\mathrm{DSH}$ & 10 & FS & Nose \\
\hline
\end{tabular}

Legend: DSH domestic short hair; age expressed as years; M male; F female; C castrated; S sterilized; nd not determined. 
Table 2. Results of histopathological lesion scores

\begin{tabular}{|c|c|c|c|c|c|c|c|c|c|c|}
\hline $\mathbf{N}^{\circ}$ & Group & EpN & Foll-N & U-C-V-P & Foll-IB & Ep-IB & Ep-CE & Foll-CE & Eos & Diagnosis \\
\hline 1 & \multirow{4}{*}{1} & - & V & V & V & - & - & V & V & Herpetic dermatitis \\
\hline 2 & & V & V & V & V & V & V & V & V & Herpetic dermatitis \\
\hline 3 & & V & V & V & V & V & V & V & V & Herpetic dermatitis \\
\hline 4 & & V & V & V & V & V & V & V & V & Herpetic dermatitis \\
\hline 5 & \multirow{6}{*}{2} & - & - & V & - & - & - & - & V & Allergy and pyoderma \\
\hline 6 & & - & V & V & - & - & - & - & V & Fly bite hypersensitivity \\
\hline 7 & & - & - & - & - & - & - & - & V & Allergy with mastocitic dermatitis \\
\hline 8 & & - & - & V & - & - & - & - & V & Allergy with mastocitic dermatitis \\
\hline 9 & & - & - & V & - & - & - & - & V & Allergy \\
\hline 10 & & - & - & V & - & - & - & - & V & Allergy \\
\hline 11 & \multirow{6}{*}{3} & V & V & V & - & - & V & - & V & Herpetic vs non herpetic dermatitis \\
\hline 12 & & - & - & V & - & - & V & - & - & Herpetic vs non herpetic dermatitis \\
\hline 13 & & V & - & V & - & & - & V & V & Herpetic vs non herpetic dermatitis \\
\hline 14 & & - & V & - & - & & - & - & V & Herpetic vs non herpetic dermatitis \\
\hline 15 & & V & V & - & - & - & - & - & V & Herpetic vs non herpetic dermatitis \\
\hline 16 & & - & V & V & - & - & V & - & V & Herpetic vs non herpetic dermatitis \\
\hline
\end{tabular}

Legend: Ep epidermal; $\mathrm{N}$ necrosis; Foll follicle; $\mathrm{U}$ ulcer; $\mathrm{C}$ crust; $\mathrm{V}$ vescicle; P pustule; IB inclusion body; Eos eosinophils; $C E$ cytopatic effect; - negative result; $\vee$ positive result. 
Tab. 3. Conventional PCR, qPCR and CISH results.

gB

TK

\begin{tabular}{|c|c|c|c|c|c|c|c|c|}
\hline \multirow[b]{2}{*}{ Case } & \multirow[b]{2}{*}{ Group } & \multicolumn{3}{|c|}{$g B$} & \multicolumn{3}{|c|}{ TK } & \multirow[b]{2}{*}{$\mathrm{CISH}$} \\
\hline & & PCR & qPCR(Cts) & $2^{-\Delta \Delta C q}$ & PCR & qPCR(Cts) & $2^{-\Delta \Delta C q}$ & \\
\hline 1 & \multirow{4}{*}{1} & V & 24.95 & $5.07 E+03$ & V & 25.02 & $7.00 E+02$ & V \\
\hline 2 & & V & 19.5 & 5.57E+04 & V & 19.53 & $7.92 \mathrm{E}+03$ & V \\
\hline 3 & & V & 22.17 & 5.37E+06 & V & 22.34 & $6.93 E+05$ & V \\
\hline 4 & & V & 16.87 & 2.53E+04 & V & 16.77 & 3.94E+03 & V \\
\hline 5 & \multirow{6}{*}{2} & - & 40.58 & - & - & $\mathrm{N}$ & - & - \\
\hline 6 & & - & 30.41 & - & - & 29.93 & - & - \\
\hline 7 & & V & 30.04 & - & - & 30.28 & - & - \\
\hline 8 & & - & 35.65 & - & - & $\mathrm{N}$ & - & - \\
\hline 9 & & - & 44.23 & - & - & $\mathrm{N}$ & - & - \\
\hline 10 & & V & 33.85 & - & V & 32.32 & - & - \\
\hline 11 & \multirow{6}{*}{3} & V & 19.6 & $7.25 E+04$ & V & 19.53 & 1.11E+04 & V \\
\hline 12 & & - & 37.78 & - & - & $\mathrm{N}$ & - & - \\
\hline 13 & & V & 28.79 & $2.00 E+03$ & V & 28.12 & $4.62 E+02$ & V \\
\hline 14 & & V & 31.73 & - & - & 31.54 & - & - \\
\hline 15 & & V & 27.2 & - & V & 26.03 & - & - \\
\hline 16 & & V & 31.09 & - & V & 32.29 & - & - \\
\hline 17 & \multirow{4}{*}{4} & - & 40.17 & - & - & $\mathrm{N}$ & - & - \\
\hline 18 & & - & 35.81 & - & - & $\mathrm{N}$ & - & - \\
\hline 19 & & - & 34.92 & - & - & 32.15 & - & - \\
\hline 20 & & V & 35.67 & - & - & 32.68 & - & - \\
\hline
\end{tabular}

Legend: 2- $\Delta \Delta \mathrm{Cq}$ fold change referred as "upregulation" of each FHV-1 target viral gene copies relative to reference gene; - negative result; $V$ positive result; $N$ no specific amplification signal. 

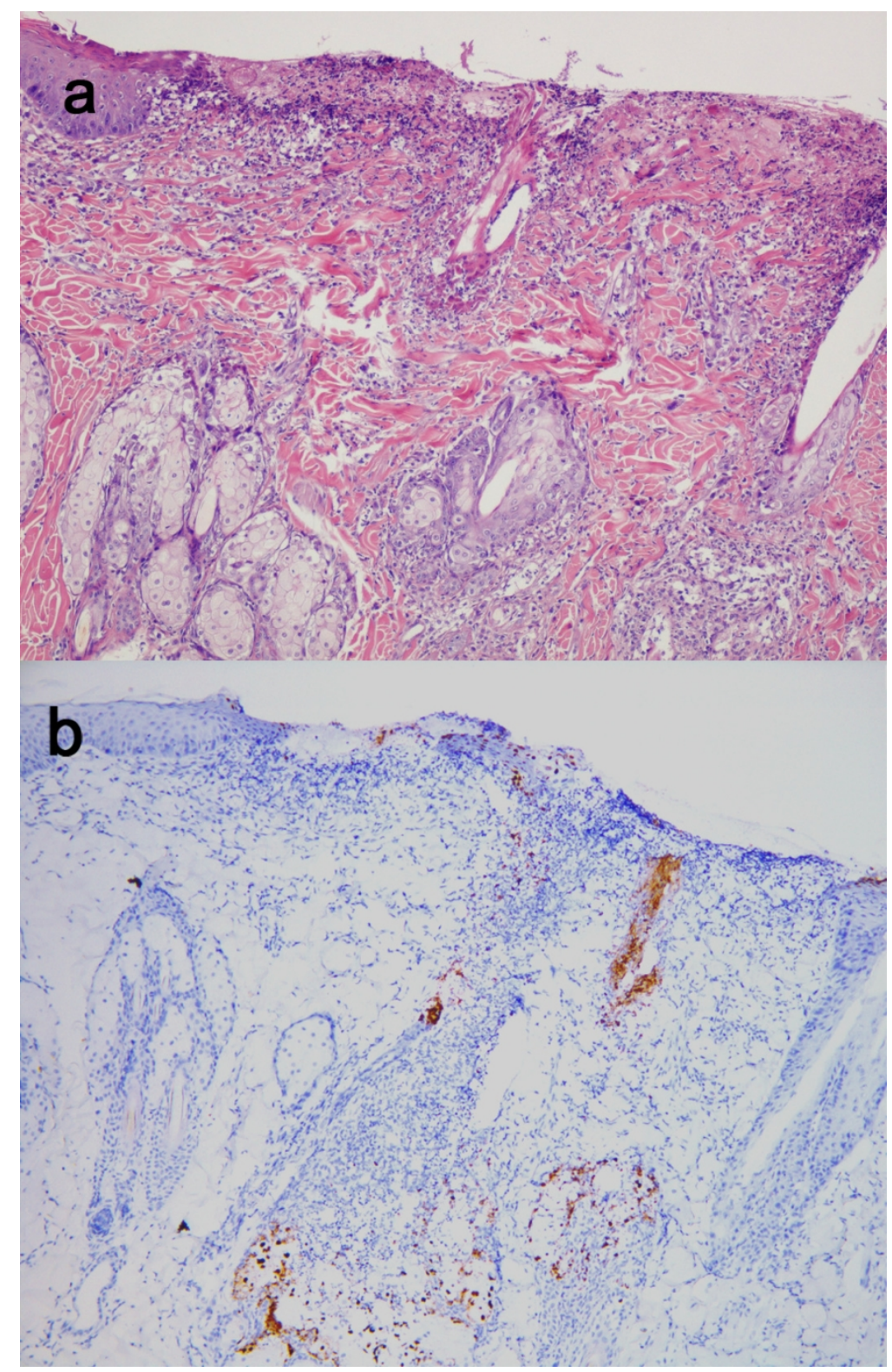

Figure 1. Feline herpesvirus dermatitis, histopathology

$90 \times 140 \mathrm{~mm}(300 \times 300 \mathrm{DPI})$ 


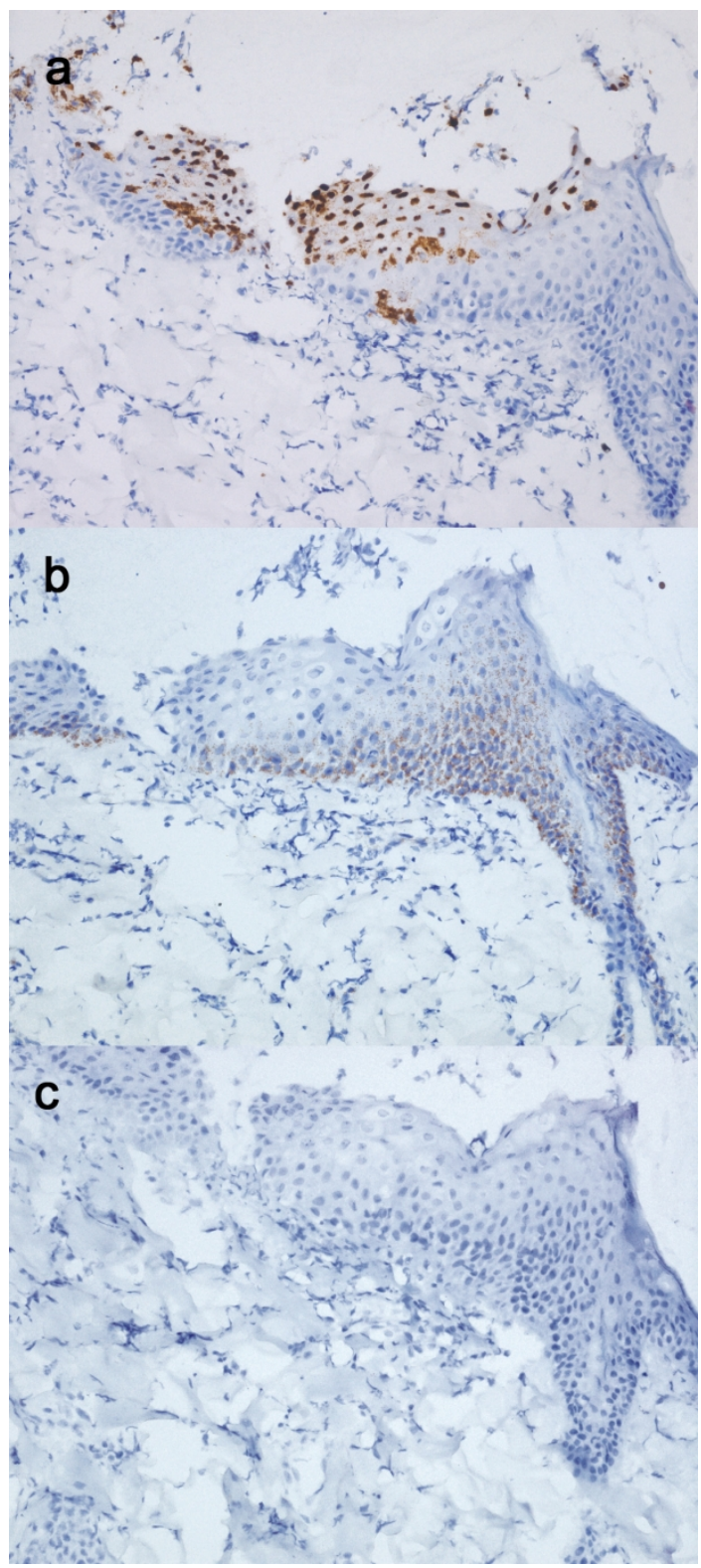

Figure 2. Feline herpesvirus dermatitis, histopathology

$90 \times 202 \mathrm{~mm}(300 \times 300 \mathrm{DPI})$ 
Supplementary : primer sequences and nucleotide position.

\begin{tabular}{lllcll} 
Reference & Primer name & Sequence & $\begin{array}{c}\text { Nucleotide } \\
\text { position }\end{array}$ & $\begin{array}{l}\text { Accession } \\
\text { Number }\end{array}$ \\
\hline \multirow{2}{*}{ Vögtlin et al, 2002 } & FHV-1 gB Fw & 5'-AGAGGCTAACGGACCATCGA-3' & $58592-58611$ & \\
& FHV-1 gB Rev & 5'-GCCCGTGGTGGCTCTAAAC-3' & $58654-58672$ & FJ478159.2 \\
& FHV-1 TK Fw & 5'-GGACAGCATAAAAGCGATTG-3' & $66291-66310$ & \\
\multirow{2}{*}{ Helps et al, 2003 } & FHV-1 TK Rev & 5'-AACGTGAACAACGACGCAG-3' & $66347-66365$ & \\
\cline { 2 - 5 } & fel28s Fw & 5'-CGCTAATAGGGAATGTGAGCTAGG-3' & $663-686$ & \multirow{2}{*}{ AF353617 } \\
& fel28s Rev & 5'-TGTCTGAACCTCCAGTTTCTCTGG-3' & $783-760$ & \\
\hline
\end{tabular}

